Bangladesh Journal of Bioethics 2015; 6(2):1-7

\title{
Medical Ethics and Medical Professionalism in Low and Middle Income (LAMIC) Countries: Challenges and Implications.
}

\author{
Albert M. E. Coleman, MD, MPH, MSC. \\ Centre of Bioethics, Medical Law and Patient Advocacy. \\ Sekondi, Ghana (W. Africa) \\ Email: albert.coleman@gmail.com.
}

\begin{abstract}
This article examines the (bio) ethical and professionalism issues that may arise in the context of medical practice in low and middle income countries (LAMIC), and the challenges this poses for medical regulatory bodies in the regions, in upholding ethics in professional practice. A quadrangle of source of the problems given rise to the breach of ethics in medical practice is identified, and suggested steps, based on ethical principles and concept, is proposed towards the resolution of the problems presented. As LAMIC progress to improve the health of its population, this endeavour should occur hand in hand with contemporary medical ethics theories, taking in context the region's ethnographic and cultural beliefs and practices.
\end{abstract}

Key words. Physicians, low and middle income countries, medical (bio) ethics, professionalism.

INTRODUCTION: The core of medical practice is the doctor-patient interaction and relationship. This can take the form of a clinic one to one encounter, or between the doctor/medical team, and the community. For the individual patient or the population that relationship plays a big part in the management of his/ her or their illness, as well as when issues of patient satisfaction is explored. The issue of doctor-patient relationship is not that straight forward, as several factors influence the balance of forces at play in that relationship. In this complex inter-play of doctor-patient relationship, the factors that influence the relationship, and the issue of the balance of force, or otherwise put the power balance at any point in the relationship; brings up the vital role of (bio) ethics and professionalism in medical practice. Several breaches immediately crop up when one then considers the quadrangle of factors [doctors, patients, (bio) ethics and professionalism], especially in LAMIC. These breaches reported on in the public domain include doctors using the professional encounters to strike up inappropriate liaisons with their patients ${ }^{1}$, doctors coercing patients to cough up extra sums of monies to access or obtain treatment, in otherwise non-fee public hospitals ${ }^{2,3}$, in some instances doctor's with-holding treatment as their asking price could not be met by public sector patients. Doctors given out sick certificates to otherwise well persons in exchange for money ${ }^{4}$, Doctors accepting bribes from patients in exchange for rendering care to patients ${ }^{5}$. Doctors engaging in clandestine organ trade and organ harvesting ${ }^{6}$ or doctors conniving with pharmaceutical companies to cheat state health systems, or encourage trading in counterfeit medications ${ }^{2}$.

The list and prevalence of breaches is long, and covers acts of commission or omission among doctors from LAMIC, (as well as in a few countries with developed economies) ${ }^{2}$. Several factors come to mind as contributing to such a situation, among which is lack of stringent professional governance, reluctance of professionals to blow the whistle on those brazenly bringing the profession into disrepute, and probably institutional denial. None the less, real life tells us that all over the world it is not the attributes of the majority who play by the rules that matter, --- (after all medical professionals are expected to play by the rules)! It is the mischief of the minority who do not work or play by the rules that make the notorious headlines, and hence bring the profession into disrepute. In the case of Sub-Saharan countries, an article describes these unethical professional behaviour in the specific country as "live hood strategies", in response to the effects of economic mismanagement, poverty and bad governance ${ }^{7}$; Or in other countries, survival related emergent strategies, mentioned elsewhere by other authors ${ }^{8-10}$. In most countries classified socioeconomically as "developed", the doctor patient relationship and ethical behaviour of doctors in their day to day practice, (and even outside the work place) are considered serious. This is so vital that the various professional governing bodies have taking strong stands on this, with medical ethics and professionalism, patient rights and protecting the patient/public being the centre of focus. Prototypes of such regulatory activity in the English speaking countries, especially on patient -doctor relationship is that of the general medical council (GMC), of England and Wales ${ }^{11}$ and the American medical association (AMA) principles of medical ethics ${ }^{12}$. Granted, in principle professional governing bodies in LAMIC have most of the core tenants of ethical medical practice enshrined in their code of practice, the evidence indicates enforcement is relatively weak, in comparison with the situation in developed 
or non-LAMIC countries ${ }^{8}$. Some of the cited reasons for this non-ethical behaviours among some LAMIC physicians being that a lot of these countries are considered "low resource" countries in terms of professional manpower, finances, oversight, governance, and the problem of level of population literacy etc. The snowball effect of these factors impacts on the local regulatory agencies to effectively do their work; these factors are even more pronounced in Sub-Saharan Africa ${ }^{8-10}$.

In the area of clinical research in most LAMIC settings, the problem of patient rights and medical (bio) ethics has been relatively pursued in recent years, in part due to collaboration with (bio) ethicists from the developed countries 13-14. On the other hand the issues of patient's rights, (bio) ethics and medical (mal) practice or patient related fitness to practice issues involving offending doctors in most developing countries; do not generally get the publicity and press to inform patients, the public or serve as warning to other doctors. The literature on this in the public domain is sparse, this being a situation in other Countries outside Western Europe, hence an effort being initiated to develop a worldwide regulatory and information exchange agency ${ }^{15}$.

BRIEF OVERVIEW OF PRINCIPLES OF MEDICAL ETHICS AND PROFESSIONALISM: The word ethics in general usage preoccupies with issues to do with moral existence and the norms that determine what is morally acceptable or not, in society at large (and in particular). Ethics as applied to medicine otherwise known as medical ethics, falls under the general umbrella of bioethics (recognised as applied ethics), and preoccupies with the application of moral philosophy principles to resolving moral problems in the field of medicine ${ }^{16}$. The principal theories underlying contemporary medical ethics stems from the various moral philosophical/ethical theories - viz consequential ethical theory, utilitarianism, deontological or duty based ethical theory and some combination of the two ${ }^{16,17}$; recognising though, the existence of other theories of ethics. For healthcare professional bodies of the like of medicine though, prescriptive "professional obligations" are primary, but not necessarily enough. Hence supererogation (beyond obligation), which relies on the moral ideal or excellence, becomes important ${ }^{17}$, therein lies the importance of virtue ethics. Clearly, the times when physician behaviour was tied to the ancient Hippocratic oath or even any of its modified forms, as oaths or dictates informing physician behaviour, cannot necessarily be described as contemporary medical ethics.

Consequential ethical theory is a consequence-based theory, with utilitarianism being a usual example of consequentialism. Utilitarianism centres primarily on maximising happiness (and for that matter minimising suffering). This is best described by Bentham as the greatest happiness for the greatest number 16. Deontological theory on the other hand is a duty based theory where call of duty is the core principle, the name Kant is very much associated with duty based moral theory, in ethics and philosophy texts. Beyond these theories several others, for example personalist, human rights based, communitarian, libertarian etc, and other moral theories exists to be looked at and applied where appropriate.

FRAMEWORKS IN NAVIGATING ETHICAL ISSUES IN MEDICAL SETTINGS: In navigating issues of medical ethics, several moral theories can be utilised, as mentioned above. On the other hand, time limited real life clinical settings, may not immediately lend itself as a theatre of moral philosophical discourse. However some moral philosophy based ethical frameworks do exist for immediate application and use in clinical settings, that can withstand the pressure of time limited clinical encounters. One such framework well known among healthcare professional (HCP), especially physicians and medical students, is "the four principles" ${ }^{19-20}$.

The four principles are autonomy, beneficence, non-malfeascence and justice. Patient autonomy is at the core of ethical medical practice in most developed countries (especially Anglo-American). This recognises the rights of the patient, and bestows upon the patient certain undeniable privileges a patient is due, in his or her capacity as a person and patient. Autonomy recognises the individual and his/her attributes of personhood, and as a rational being. Beneficence is the duty only to do good in the interest of the person/patient. Non-malfeascence, or the duty not to cause harm to the person/patient, otherwise the duty of the doctor not to abuse his/her professional role in the patient doctor relationship ${ }^{16}$. Finally justice primarily focuses on adjudication of competing interest between people; or for communities, distributive justice in allocation of scarce resources. 
Another framework utilised increasingly in clinical settings is the four boxes approach. In this case ethical dilemmas arising are looked at from the point of view of the patient, medical necessity, quality of life and contextual or other factors $^{21}$.

A third frame work emphasizes the healthcare professional (HCP) and patient dyadic relationship under the guise of care ethics, which combines elements of feminine ethics, Levinasian ethics and virtue ethics. Care ethics seeks to ensure the patient "does not fall through the web of vulnerability" ${ }^{22}$. In this case the importance of a "virtuous" character, in combination with a caring nature, and an ability to perceive the patient's suffering in the light of the "thou and I" Levinisian concept ${ }^{23}$, is key to ensuring the suffering patient does not slip through the web of vulnerability, and get lost. These mentioned frameworks are meant to quickly prime and orientate physicians, and act as ethical road maps, to guide their day to day doctor - patient interaction, in an otherwise hectic and time limited clinical setting.

DISCUSSION: Medical practice worldwide over and above the Hippocratic Oath is governed by normative or moral philosophical theories as enshrined in (contemporary) medical ethics ${ }^{16}$. Contemporary medical ethics is considered a sub-field of bioethics (informed in a large part by normative based scholarship from the field of philosophy). In developed countries, just as with governance, there are checks and balances which ensures good state governance, and in that sense good professional codes of practice. Unfortunately one cannot say that with confidence about similar attitudes to governance in most LAMIC settings ${ }^{2}$. Notwithstanding even in developed countries, there is the occasional slip in the execution of the mechanism of governance and equally of the code of practice of professionals 2. A case in point in England was the Harold Shipman saga, which eventually changed the internal composition and some operational procedures of the oversight role of the professional governing body of medicine, and part of the code of practice of medicine (18). Unfortunately in LAMIC settings, as mentioned earlier there appears to be an array of factors that may contribute to systematic abuse of the patient-doctor relationship by physicians, relative to the situation in developed countries ${ }^{8-10}$.

The issue of relatively high illiteracy rates in developing countries, could be contributory too. There have been case studies indicating that doctors in some LAMIC settings may use the issue of illiteracy to exert paternalistic pressure in the patient-doctor relationship, with doctors adopting the "know best" attitude ${ }^{19}$. In some LAMIC regions, relatively high poverty levels coupled with poor governance has contributed to an increasing pool of vulnerable groups in the population. As one author writes "vulnerable individuals and groups are subjected to exploitation, and exploitation is morally wrong" ${ }^{20}$, hence a need for vulnerability to be a pre-occupation of bioethics. Of note and of some relevance is that a fair number of LAMIC, are plagued with issues of corruption and human rights abuses; these problematic factors, may probably filter down and impact on the doctor-patient interaction/setting (although admittedly not necessarily). I raise this issue as corruption and human rights abuse, do not occur in a vacuum, and are especially relevant negative forces, in a setting of power imbalance (as the like of the doctor-patient-relationships). Admittedly if these two problematic factors rear its head in the doctor-patient interaction, medical ethics and professionalism stands to lose. Issues of ethics, governance and regulation of medical practice, among others has been the focus of all regulatory organisations that oversees the practice of medicine in almost all countries. However when one compares regulatory practices in the developed nations to that in most LAMIC settings, the standard and thresh-hold of how those that breach these ethical guides of good medical practice are held accountable may differ ${ }^{24}$. $A$ case in point to illustrate the intersection of poverty, vulnerability, corruption in medicine and medical practice, corruption in medical education, medical regulation and medical ethics/bioethics in a LAMIC setting is the example in India, considered one of the largest (if not the largest) democracies; which prompted an article in the Indian journal of medical ethics ${ }^{25}$. I am sure what the author was writing about is not a situation of concern only for India, but occurs in many LAMIC settings, except that in this case the article zoomed in on the situation in India.

Of importance in medical practice is to re-enforce the notion of respect for the patient/community, not respect in the semantic sense but the special sense relevant to the doctor-patient relationship ${ }^{26}$. This in a way is akin to Kant's notion of rational person or agent, - being an end in him/herself, and not a means to an end ${ }^{27}$. As to the poverty and governance issues in some developing countries that tend to contribute to questionable ethical behaviour; governments in those countries have to seriously tackle the factors and machinery of perpetual poverty. This can be achieved by way of tackling social injustice, sound economic policies and promoting appropriate socio-political development ${ }^{28}$. This eventually will free its citizenry (including doctors and other health staff), from the attribute or 
survival factors that impact on good ethical practices. This last point is somehow in line with the ethics of liberation theology ${ }^{29-30}$, which attempts to debate problems of this sort.

Considering the ethics of doctor-patient interaction models, (paternalistic, independent, autonomy and passive) (31), medical practitioners in some LAMIC settings tend to be paternalistic, this most times tends to down play patient autonomy in the interaction ${ }^{32}$. This brings me to the other important thing in patient-doctor interactions in developed countries (especially Anglo-American settings), that is pronouncements on "medical professionalism" ${ }^{33}$. This new professionalism among other things recognise and embody some of the moral and ethics based issues previously mentioned - autonomy ${ }^{17}$, personhood/rational agent ${ }^{27}$ and respect ${ }^{26}$. Obviously for a meaningful change for physicians from LAMIC settings to meet ethical expectations demanded by the profession, there need to be a shift to discard the current style of doctor -patient interaction that potentially could set the stage for unethical practices. Instead they and their national regulatory bodies should embrace seriously the tenets of medical ethics and revamped concept of medical professionalism, as mentioned earlier ${ }^{33}$. Whilst on the subject of professionalism, one cannot ignore an important attribute of a professional as applied to physicians mentioned earlier, that of going beyond the obligation imposed by the profession, otherwise referred to as supererogation ${ }^{17}$. This denotes not only competence as a member of a professional body, but the use of this competence in the best interest of the patient and where the situation demands, going over and above the usual obligations demanded by the profession; all this against a background of trust. This all encompassing professional attribute is a virtue based ethics, or specifically virtue in the ethics of the medical profession. It is this that confers the "special status to those of the medical profession in society at large" ${ }^{34}$. Here again, the task is to effect such a paradigm shift in the profession in developing countries. One can realise that a fundamental or basic starting threshold for tackling the problems of moral and ethical importance in the practice of medicine in these regions, is a strong and energetic drive to train medical practitioners in the region in the principles and practice of contemporary medical ethics. In medical schools in the region, the curriculum of medical schools should have a compulsory biomedical ethics component ${ }^{24,34}$, as increasingly pertains in the curriculum in most (if not all) developed countries, rather than being offered as an elective ${ }^{35}$. This should extend also to post-graduate medical education ${ }^{36,37}$, with accelerated training of medical ethicist as with other medical specialties. Eventually (and hopefully) a critical mass of medical ethicist can come into being in LAMIC settings to teach, form institutional ethics board, research ethics committees, think tanks etc. This is not a developed or western country ideal, but rather an inescapable relevance ${ }^{38}$ for the maintenance and continued improvement of the professional level of practitioners of the medical profession. Additionally this ensures accountability of the profession and eventually empowers our patients to participate equally in the promotion and maintenance of their health. One would argue some restraint about medical regulatory bodies adopting what may be seen as culturally unsuitable moral principles or ethical guidelines ${ }^{39-40}$. An approximation of such a worry was expressed by an academic in North America, commenting on ethical practice by black physicians based on the phenomenon of "belonging" and "negriscence building", in their professional interaction with fellow black patients ${ }^{41 .}$ This as opposed to what he considered a white culture based ethical theory/practice. I am afraid any analogous reasoning along those lines in the case of the medical profession and regulatory bodies in LAMIC settings in raising their level of ethical practice, to levels as practised and maintained in developing countries is nothing short of "ethical relativism" ${ }^{40}$.

On the other hand considering the world -wide variety of cultures, some attention to specific cultural norms in ethical decision making against a background of contemporary ethical principles may prove good practice in the long term. Another school of ethical thinking however argues that there are core ethical principles that are universal and nonnegotiable, across cultural lines ${ }^{42}$.

CONCLUSION: All said there is relatively an obvious gap in medical ethics practices and adherence in LAMIC settings in comparison to what pertains in most developed economy settings (even for some LAMIC settings otherwise classified as "higher middle developed countries") ${ }^{43}$. These gaps may be attributed to various cultural, social and finance driving factors as elaborated in previous chapters, as well as a relative dearth of medical ethics teaching in medical education in LAMIC settings. Medical (bio) ethics education is considered essential in the formative stages of undergraduate medical education, and the life span of the practising physician. It is not expensive to acquire as the likes of some of the out of reach diagnostic equipment and medical procedures, even for those in developed economy settings. On the other hand what is required for its strong incorporation in LAMIC settings is a commitment by medical regulatory bodies, professional associations, medical schools and governments to put in 
place the directives and mechanisms to ensure that medical (bio) ethics is whole heartedly incorporated in medical education and practice, as done in "developed "regions ${ }^{14-15}$. Hopefully such an education driven measure incorporating some elements of social marketing initiatives may eventually lead to a change in attitude of most medical practitioners in LAMIC settings, towards an (bio) ethics driven professional attitude coupled with their technical expertise; leading to improved doctor patient relations, increased patient satisfaction, increased patient outcome measures as well as upholding of patient dignity in LAMIC settings.

COMPETING INTEREST: None to declare.

\section{REFERENCES:}

1. Simms G. Hawks and vultures coming home to roost. Jamaica Gleaner. Published: Sunday/March 1, 2009. www.mobilejamaicagleaner.com20090301/focus/focus3php. Accessed: 30/09/2014.

2. Savedoff W and Hussman K, 'Why are health systems prone to Corruption?' in Transparency International's Global Corruption Report 2006 (London: Pluto Press, 2006).

3. Myjoyonline.com. Doctors to face probe. www.myjoyonline.com/tools/print/printnews. asp?contentid=775. Source: Daily Graphic: 17/01/2007. Accessed: 30/09/2014.

4. Azure JP. Unseemly medical practice. Jamaica Gleaner, letter. Friday/February 25, 2005. www.jamaica-gleaner.com/gleaner/20050225/letters/letters2.html. Accessed: 30/09/2014

5. Fan R. Corrupt practices in Chinese medical care: the root in public policies and a call for Confucian-market approach. Kennedy Inst Ethics J. 2007 Jun; 17(2):111-31.

6. Jafarey A, Thomas G, Ahmad A, Srinivasa S. Asia's organ farms. Indian J Med Ethics 2007 Apr-Jun; 4(2): 52-3.

7. Owusu F. Live hood strategies and performance of Ghana's health and education Sectors: exploring the connections. Public administration and development. Vol 25(2): 157-174. John Wiley \& sons. 2005.

8. Roenen C, Ferrinho P, Van Dormael M, Concieicao MC, Van Lerberghe W. How African doctors make ends meet: an exploration. Tropical Medicine and International Health. Vol2 ;(2): 127-135. February 1997.

9. Muula AS, Maseko FC. How are health professionals earning their living in Malawi? BMC Health Services Research 2006, 6: 97. doi: 10.1186/1472-6963-97. www.biomedcentral.com/1472-6963/6/97. Published: 09 August 2006. Accessed: 30/09/2014.

10. Olweny C. Bioethics in developing countries: ethics of scarcity and sacrifice. J Med Ethics. 1994 Sep $20 ;$; 3): 169-74.

11. General Medical Council. Good Medical Practice, 2014. Available at www.gmc-uk-org. Accessed 29/09/2014.

12. American Medical Association. The Principals of Medical Ethics. AMA press, Chicago USA. 2004.

13. Cox P. Codes of medical ethics and the exportation of less-than-standard care. Int J Appl Philos. 1999 Fall; 13(2): 177-85.

14. Lackey DP. Clinical research in developing countries: recent moral arguments. Cad Saude Publica, Rio de Janeiro, 18(5): 1455-1461, 2002.

15. Marchant R. You show me yours and I'll show you mine-medical mobility and regulatory cooperation. BMJ Careers pp170-172. $15^{\text {th }}$ October 2005.

16. Gillon R. Philosophical Medical Ethics. Wiley medical. June 2000.

17. Beauchamp T L, Childress J F. Principals of Biomedical Ethics. Fifth edition. Oxford University press 2001.

18. The Shipman inquiry. Fifth report. Safeguarding Patients. Lessons from the past. Proposals for the future. www.shipman-inquiry.org.uk/fifthreport.asp. Published 9 December 2004. Command paper. CM 6394. Accessed 30/09/2014. 
19. Luna F. Paternalism and the argument from illiteracy. Bioethics. $1995 \mathrm{Jul} ; 9(3-4) ; 283-90$.

20. Macklin R Bioethics, vulnerability, and protection. Bioethics. 2003 Oct; 17(5-6): 472-86.

21. Jonsen AR, Siegler M, Winslade WJ. Clinical Ethics. A practical approach to ethical decisions in clinical medicine. $6^{\text {th }}$ edition. McGrawHill Medical. New York. 2006.

22. Tronto J. An ethic of care. In: Holstein M and Mitzen $P$ (eds). Ethics in community-based elder care. Pp. 60-68. New York, Springer Publishing, 2001.

23. Diedrich WW, Burggraeve R, Gastmans C. Towards a Levinasian Care Ethics: A Dialogue between the Thoughts of Joan Tronto and Emmanuel Levinas. Ethical Perspectives. Journal of The European Ethics Network. 13, no. 1 (2003): 33-61.

24. Ogundiran T O. Enhancing the African bioethics initiative. BMC medical education. 2004, 4:21 doi: 10.1186/1472-6920-4-21. Published 15 October 2004. www.biomedcentral.com/1472-6920/472-6920/4/21 Accessed: 30/09/2014.

25. Chattopadhyay S. Black money in white coats: Wither medical ethics. Indian Journal of Medical Ethics JanuaryMarch 2008; 5(1):20-21. Accessed 07/09/15

26. Beach M C, Duggan PS, Geller CKC. What does respect mean. Exploring the moral of health professionals to respect patients. J. Gen. Intern Med 2007 May; 22(5): 692-695

27. Kant I. Critique of pure reason. In: Kemp Smith, N. Ed. Immanuel Kant's critique of pure reason. London; Macmillan, 1993.

28. Sen A. Development as Freedom. Oxford university press. 1999.

29. Boff L, Boff C. A concise history of Liberation theology. From the book "Introducing Liberation theology". Orbis books. Available at www.landreform.org/boff2.htm Accessed: 30/09/2014.

30. Anjos M F. Medical ethics in the developing world: A liberation theology perspective. J of Med Philos. 1996 Dec; (6): 629-37.

31. Emmanuel E J, Emmanuel L L. Four models of the physician-patient relationship. J Am Med Assoc 1992; 267:2221-2226.

32. Qiqwai W. Patient autonomy: Reflections from a developing country. Letter. American family physician. American Academy of family physicians. April 12005.

33. Medical Professionalism Project (ABIM foundation, ACP-ASIM foundation, European federation of internal medicine). Medical professionalism in the new millennium: A physician charter. Annals of Internal Medicine February 2002. Volume 136 Number 3. 5.

34. Pellegrino E D. Professionalism, profession and the virtues of the good physician. The Mount Sinai Journal of Medicine 2002; 69 (6) 378-384.

35. Swick HM, Szenas P, Danoff D, Whitcomb ME. Teaching professionalism in undergraduate medical education. JAMA 1999; Sep1; 282(9):830-2

36. Wray SR, Parshad O, Young LE. Ethics and law in the medical curriculum, a university of the West Indies perspective. Med Law 1993. 121(1-2):41-5.

37. Walrond ER, Jonnalgadda R, Hariharan S, Moseley HS. Knowledge, attitudes and practice of healthcare ethics and law among doctors and nurses in Barbados. Med Ethics. 2006 Jun 9; 7 E7.

38. Carrese JA, Sugarman J. The inescapable relevance of bioethics for the practicing clinician. Chest 2006 Dec; 130(6): 1864-72. 
39. Kleinnman A, Benson P. Culture, moral experience and medicine. Alexander Richman commemorative lecture. The Mount Sinai Journal of Medicine 2006; 73(Oct 6): .834-839.

40. Turner L Medical ethics in a multicultural society. J R Med 2001; 94:592-594.

41. Griffith EE. Personal narrative and an African-American perspective on medical ethics. J Am Acad Psychiatry Law 2005; 33(3):371-81.

42. Baker R. A theory of international bioethics: the negotiable and the non-negotiable. Kennedy Inst. Ethics J. 1998 Sep; 8(3):233-73

43. Holt E. Slovak bribery case sparks wider debate in eastern Europe. The Lancet 2015; 385 (June 6): 2242. www.thelancet.com. Accessed June $5^{\text {th }}, 2015$. 